\title{
RECICLAGEM DE BORRACHA DE PNEU EM FORNO ELÉTRICO A ARCO
}

Douglas Ferreira Ambrosio ' Flavio Beneduce ${ }^{2}$

\section{Resumo}

O objetivo do presente trabalho é avaliar o uso de borracha triturada de pneu como carburante substituto do coque na etapa de refino de um forno elétrico a arco na produção de aço 1020 . Testou-se durante dezenas de corridas situações com injeção de borracha em 4 níveis diferentes para substituir o coque: $0 \%$ de borracha, $33 \%$ de borracha, $66 \%$ de borracha e $100 \%$ de borracha. Em todas as corridas testadas foram coletadas amostras do aço e da escória no momento antes do vazamento. As amostras foram analisadas através de um espectrômetro de RX. Os resultados obtidos mostraram que é possível a substituição total do coque pela borracha de pneu triturada sem incorrer prejuízos ao processo. Não se observou incorporação de Enxofre no aço, preocupação esta que existia pelo fato da borracha triturada conter teores mais elevados deste elemento em comparação com o coque.

Palavras-chave: Injeção de coque; Borracha de pneu; Forno elétrico a arco; Combustíveis alternativos.

\section{RECYCLING OF TIRE RUBBER IN ELECTRIC ARC FURNACE}

\begin{abstract}
The purpose of this research is to evaluate the use of grinded wasted rubber tires as a carbon source to substitute the coke during the refine in an Electric Arc Furnace to produce steel - grade 1020. It was tested during several heats 4 different levels of rubber injection to substitute coke: $0 \%$ of rubber, $33 \%$ of rubber, $66 \%$ of rubber and $100 \%$ rubber. Samples of the steel and the slag were taken before the tap. The samples were analyzed in the RX Spectrometer. The results showed that is it possible to substitute completely the coke with rubber without causing any issues to process. The sulfur content in the rubber did not contaminated the steel, although the rubber contains higher sulfur compared to the coke. Keywords: Coke injection; Wasted rubber tires; Electric arc furnace; Alternative fuels.
\end{abstract}

\section{INTRODUÇÃO}

Siderurgia é hoje a indústria que mais consome energia, responsável por aproximadamente $5 \%$ de todo consumo mundial de energia [I]. É fundamental para a indústria do aço encontrar fontes alternativas de energia, tanto por uma questão de competitividade quanto por questões ambientais, uma vez que a cada dia aumentam as demandas por energia e crescem as pressões para diminuição do uso de combustíveis fósseis [2].

Nesse contexto observa-se que a produção de aço através dos fornos elétricos a arco tem aumentado nas últimas décadas pelo fato desses fornos operarem com baixas demandas de energia e custo, entre outros [3]. Além disso, os fornos elétricos a arco podem operar com diversos tipos de matéria prima, o que garante certa flexibilidade.
No processo de fusão da sucata emprega-se energia elétrica e energia química [3].

A energia química é fornecida através da combustão do gás natural e coque, além de outras reações como oxidação do Ferro e outros elementos. O coque derivado do petróleo é um dos mais importantes carburantes utilizados na siderurgia. Quando o coque é injetado na carga líquida do forno durante a corrida, o carbono contido reage com o $\mathrm{FeO}$ da escória gerando gás $\mathrm{CO}$ que promove a espumação da escória. A escória espumante tem algumas vantagens tais como: melhoria da transferência de energia do arco elétrico para o banho, proteção dos painéis refrigerados da radiação térmica e redução do ruído [4]. Apesar das vantagens que a injeção de coque promove no processo,

'Gerdau Aços Longos, São Paulo, SP, Brasil. E-mail: dougbrosio@gmail.com

${ }^{2}$ Departamento de Engenharia Metalúrgica e de Materiais, Escola Politécnica, Universidade de São Paulo - USP, São Paulo, SP, Brasil.

2176-1523 (C) 2019 Associação Brasileira de Metalurgia, Materiais e Mineração. Publicado pela ABM. Este é um artigo de acesso aberto distribuído sob os termos da licença Creative Commons CC BY-NC-ND (Attribution-NonCommercial-NoDerivs) - https:// creativecommons.org/licenses/by-nc-nd/4.0\%. 
o coque é uma fonte de carbono derivado de combustíveis fósseis e apresenta preço elevado e sujeito as oscilações do mercado do óleo e gás.

A borracha é um polímero que possui longas cadeias de hidrocarboneto e tem composição química e propriedades que permitem que ela seja um potencial substituto de carburantes, como o coque [5]. A borracha apresenta diversas vantagens em comparação com o coque, como maior teor de matéria volátil, baixa geração de cinzas e baixa umidade [6].

Do ponto de vista ambiental a borracha é mais interessante que o coque. $O$ conteúdo de borracha natural num pneu responde por cerca de $30 \%$, e pode ser considerada como sem impacto na geração de gases do efeito estufa, devido ao carbono sequestrado no plantio das árvores que geram o látex (Atech Group, 200 I). Além disso, a destinação de pneus tem sido um desafio crescente em diversas partes do mundo. $\mathrm{O}$ aumento das frotas automotivas aumenta a geração de pneus usados e soluções inteligentes para o descarte se fazem cada vez mais necessárias. Além das vantagens ambientais, o pneu apresenta custo inferior ao coque e, em muitos casos, é até mesmo possível monetizar o processamento desse material no forno elétrico [5].

Como mostra a Tabela I a borracha triturada de pneus possui uma composição química que permite que ela atue como um potencial substituto do coque como elemento carburante para o forno elétrico, como pode ser visto na tabela abaixo [6,7]. As principais diferenças são o menor teor de cinzas da borracha, que é uma vantagem, o maior teor de voláteis, que pode ser uma vantagem na etapa de escória espumante e o maior teor de enxofre, que pode ser uma desvantagem quanto a composição do aço e/ou emissão para a atmosfera. Finalmente, a borracha possui um maior teor de carbono total que é também uma vantagem.

Apesar do conteúdo maior de enxofre presente na borracha, nos testes em escala industrial na Siderúrgica One

Tabela I. Composição química e poder calorííco do coque metalúrgico e borracha de pneu

\begin{tabular}{lcc}
\hline \multicolumn{3}{c}{$\begin{array}{c}\text { Composição química e poder calorífico do coque } \\
\text { metalúrgico e borracha de pneu }\end{array}$} \\
\hline & $\begin{array}{c}\text { Coque } \\
\text { Metalúrgico (\%) }\end{array}$ & $\begin{array}{c}\text { Borracha de pneu } \\
\text { (\%) }\end{array}$ \\
\hline Umidade & 1,3 & 0,9 \\
Cinzas & 18,3 & 5,7 \\
Matéria Volátil & 3 & 63,2 \\
Carbono Fixo & 73,6 & 30,2 \\
Carbono Total & 77,7 & 83,8 \\
Enxofre & 0,28 & 2 \\
Hidrogênio & $1,1 \mathrm{I}$ & 7,6 \\
Nitrogênio & $\mathrm{I}, 21$ & 0,25 \\
Poder Calorífico(MJ/kg) & $28-31$ & 40,16 \\
\hline
\end{tabular}

Fonte: Adaptado de [6,7].
Steel da planta Sidney Steel Mill não se observou incorporação de enxofre no aço, conforme observa-se na Tabela 2.

Além da composição semelhante, coque e a borracha tem um comportamento cinético semelhante. A Figura I mostra um experimento no qual é comparada a taxa de geração total de gás em função do tempo. Pode-se notar que a mistura de borracha e coque possui uma taxa de geração de gás ligeiramente superior do que o coque puro. Esse fato pode ser atribuído ao Hidrogênio contido (voláteis) em maior proporção na borracha do que no coque [7].

Este trabalho tem por objetivo analisar e discutir a viabilidade técnica do uso da borracha triturada de pneu como substituto do coque como material carburante através de injeção pneumática na etapa de refino de um forno elétrico a arco.

\section{PROCEDIMENTO EXPERIMENTAL}

Foram realizados 120 testes de injeção de borracha triturada na planta da Gerdau São Paulo em Araçariguama, em um forno elétrico a arco trifásico com capacidade de 108 t. $O$ forno possui 3 injetoras de carburante, $2 \mathrm{em}$ operação e I de reserva.

O material carburante é armazenado em 3 silos separados, de $30 \mathrm{~m}^{3}$ cada, e que abastecem cada uma das 3 injetoras.

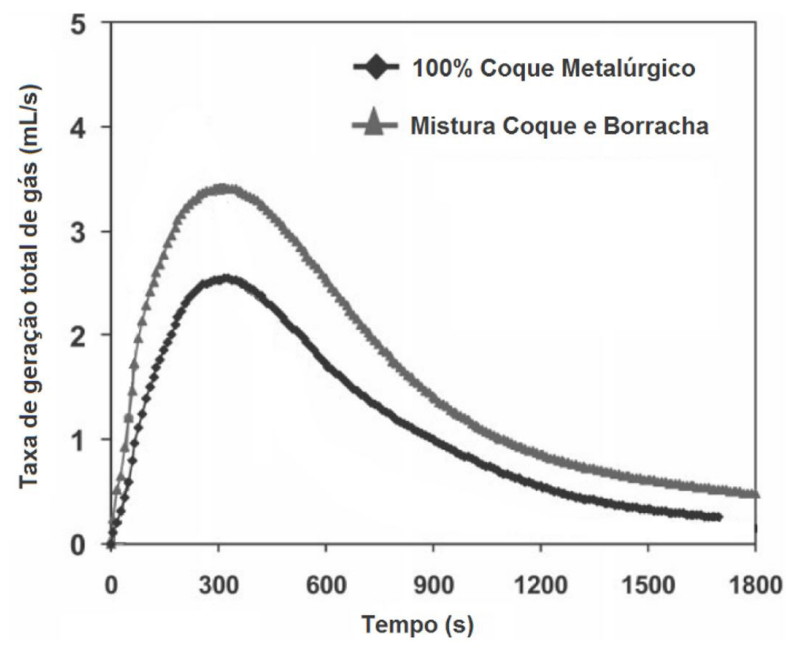

Figura I. Taxa de Geração Total de Gás em função do Tempo para Coque e mistura de Coque e $25 \%$ de Borracha a $1550^{\circ} \mathrm{C}$. Fonte: Adaptado de Sahajwalla et al. [7].

Tabela 2. Enxofre no aço na planta Sidney Steel Mill (média anual)

\begin{tabular}{ccc}
\hline \multicolumn{3}{c}{ Enxofre no aço na planta Sidney Steel Mill (média anual) } \\
\hline Ano & $100 \%$ coque & Borracha e Coque \\
\hline 2007 & $0,0213 \% \mathrm{~S}$ & $0,0219 \% \mathrm{~S}$ \\
2008 & $0,0226 \% \mathrm{~S}$ & $0,0224 \% \mathrm{~S}$ \\
\hline
\end{tabular}

Fonte: adaptado de Zaharia [6] 
A borracha de pneu triturada foi processada e classificada utilizando peneiras na faixa entre 3 e $8 \mathrm{~mm}$. A borracha era isenta de metais, tecidos, nylon e fibras. $\mathrm{Na}$ Figura 2 pode-se observar $\mathrm{o}$ aspecto geral do material utilizado nos testes.

Os testes de injeção de borracha triturada foram realizados na produção de um aço AISII020D. Durante os testes procurou-se manter inalteradas todos os demais parâmetros de processo. Corridas de partida, após parada do forno, e corridas nas quais houve alteração da carga fria foram retiradas da base de dados para avaliação dos resultados.

Foram testadas 4 proporções na injeção de borracha como é mostrado na Figura 3. Foi utilizado um total de $600 \mathrm{~kg}$ por corrida de combustível (coque + borracha).

Em toda corrida foi retirada uma amostra de aço e uma amostra de escória antes do vazamento, as quais foram analisadas utilizando um espectrômetro de emissão óptica e um espectrômetro de fluorescência de $R X$, respectivamente. Os elementos foram analisados foram Carbono, Cromo, Cobre, Manganês, Molibdênio, Nióbio, Níquel, Fósforo, Enxofre, Silício, Estanho, Zinco, Chumbo e Arsênio no aço e $\mathrm{CaO}, \mathrm{SiO}_{2}, \mathrm{FeO}, \mathrm{MnO}, \mathrm{MgO}, \mathrm{Al}_{2} \mathrm{O}_{3}, \mathrm{P}_{2} \mathrm{O}_{5}, \mathrm{TiO}_{2}, \mathrm{~S}$ e F na escória.

\section{RESULTADOS E DISCUSSÃO}

Foram analisados os níveis de Enxofre no aço para as 4 proporções diferentes utilizadas de coque e borracha. Utilizou-se para as análises estatísticas o software Minitab. Primeiramente foi realizada uma análise estatística por meio da ferramenta box-plot no qual está definido os valores da média e do intervalo de confiança da medida (Figura 4), de forma a avaliar os resultados e remover os pontos com desvio excessivo (outliers em asterisco), e depois agrupou-se os dados, deixando-se fora da análise os pontos que não estão contidos em nenhum dos 4 intervalos, mostrados na Figura 5. Os dados foram agrupados conforme a classificação de proporção de borracha utilizada:

$$
\begin{aligned}
& \mathrm{PI}=0 \% \text { borracha }=0 \%<\mathrm{p}<10 \% \\
& \mathrm{P} 2=33 \% \text { borracha }=23 \%<\mathrm{p}<43 \% \\
& \mathrm{P} 3=66 \% \text { borracha }=56 \%<\mathrm{p}<76 \% \\
& \mathrm{P} 4=100 \% \text { borracha }=90 \%<\mathrm{p}<100 \%
\end{aligned}
$$

Após o tratamento estatístico preliminar foi realizada a análise de variância (ANOVA) para verificar se há diferenças no teor de Enxofre no aço entre os grupos com intervalo de confiança de $95 \%$ sob duas hipóteses:

I. Hipótese H0: não há diferença significativa entre os grupos

2. Hipótese HI: há diferença significativa pelo menos entre dois grupos

O resultado de $P_{\text {valor }}=0,994>0,05$ mostrou que não há evidências estatísticas suficientes para rejeitar $\mathrm{HO}$.
Apesar dos níveis maiores de Enxofre na borracha triturada comparado ao coque, não foi observado um aumento estatisticamente significativo do nível de Enxofre no aço,

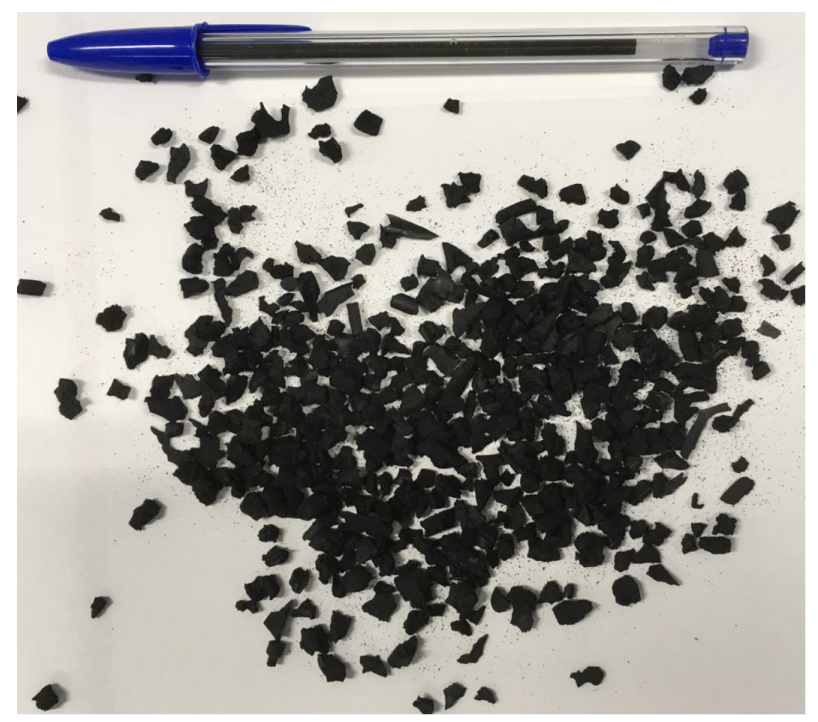

Figura 2. Detalhe da borracha de pneu triturada injetada no forno elétrico.

Proporções na Injeção de Coque e Borracha

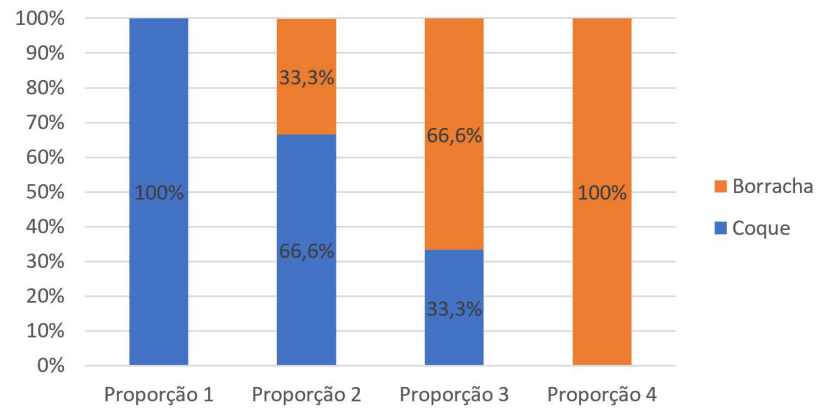

Figura 3. Níveis de injeção de coque e borracha.

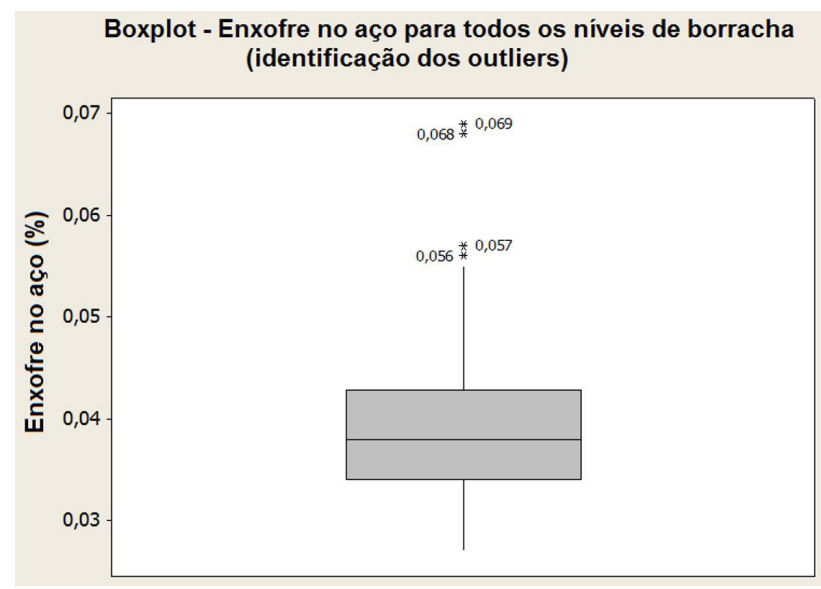

Figura 4. Boxplot - enxofre no aço para todos os níveis de borracha (identificação de outliers). 


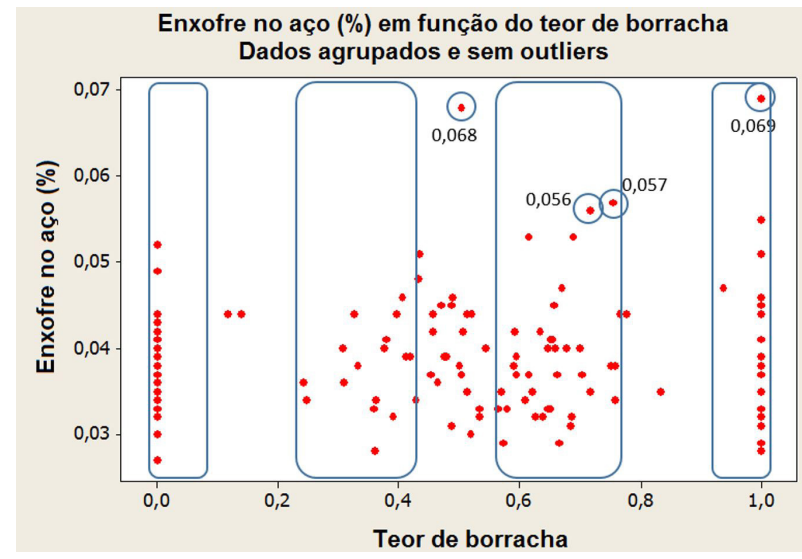

Figura 5. Enxofre no aço (\%) em função do teor de borracha - dados agrupados e sem outliers.

até porque a quantidade adicional de enxofre não seria detectada no analisador. $O$ teor de enxofre aumentaria, no caso mais crítico ( $100 \%$ de borracha), cerca de $0,0012 \%$ fora do limite de detecção do equipamento. De qualquer forma, a discussão do local em que o enxofre vai parar continua sendo importante tanto por razões de qualidade do metal quanto por questões ambientais. Esse fato reitera os dados obtidos em literatura nos testes feitos em outras siderúrgicas.

Duas hipóteses existem para explicar qual o destino dessa quantidade maior de Enxofre presente na borracha:

Hipótese I: o Enxofre fica retido na escória, que é improvável dado o nível de oxidação da escória de cerca de $25 \% \mathrm{FeO}$, portanto com uma baixa capacidade de sulfeto e confirmado pelos teores de $\mathrm{S}$ constantes analisados na escória (cerca de $0,07 \%$ S).
Hipótese 2: o Enxofre vai para o sistema de coleta de gases na forma de $\mathrm{SO}_{2}$. Este fato pode ser evidenciado pelos testes semelhantes realizados no mesmo forno elétrico, como reportado por Massambani [8]. Nesses testes foram adicionadas I t de materiais poliméricos na da carga fria do mesmo forno elétrico empregado no presente trabalho, em condições semelhantes, observando-se um aumento significativo do $\% \mathrm{SO}_{2}$ no gás da saída, ficando dentro das legislações europeia e paulista.

Vale mencionar que variáveis como, composição química da escória, tempo tap to tap, tempo de power on, consumo de energia, eletrodos, refratários e oxigênio foram analisadas sem qualquer alteração significava dos valores.

\section{CONCLUSÃO}

O presente trabalho possibilitou concluir que o uso de borracha triturada a partir de pneus inservíveis como substituto do coque, empregado como combustível na elaboração de aços em forno elétrico a arco, não ocasiona um aumento dos teores de Enxofre no aço. Esse resultado é um indicativo de que a borracha é um potencial substituto do coque como carburante na injeção, apresentando viabilidade técnico-operacional e vantagens relacionadas ao meio ambiente e custo.

\section{Agradecimentos}

Os autores agradecem ao Departamento de Metalurgia e Materiais da Universidade de São Paulo, à Gerdau e todos os colaboradores que estiveram envolvidos na elaboração deste trabalho.

\section{REFERÊNCIAS}

I International Energy Agency. Energy balance flows - 2016. USA: IEA; 2016 [acesso em 19 out. 20 I8]. Disponível em: http://www.iea.org/Sankey/index.html

2 Rossi D. Influência da proporção entre as vazões de oxigênio e gás natural do sistema de injeção na eficiência energética de um forno elétrico a arco [dissertação]. Porto Alegre: Programa de Pós-graduação em Engenharia de Minas, Metalúrgica e de Materiais, Universidade Federal do Rio Grande do Sul; 2014 [acesso em 19 out. 2018]. Disponível em: http:// www.iea.org/Sankey/index.html

3 Fortes RAFO, D'Abreu JC, Avillez RR. Melting rates of ferrous materials in the EAF. In: Proceedings of the Fruehan Symposium on Physical Chemistry of Sustainable Metal Processing; 20I I; Pittsburg. Pittsburg: [s.n.]; 20I I. p. 107-127.

4 John AL. Melhorias no desempenho dos injetores supersônicos em operação em um forno elétrico a arco. Porto Alegre: Programa de Pós-graduação em Engenharia de Minas, Metalúrgica e de Materiais, Universidade Federal do Rio Grande do Sul; 2009.

5 Gorni AA. Aproveitamento de sucata de pneus e resinas plásticas em forno elétricos a arco. In: Anais da Feira e Congresso Plastshow; 2008; São Paulo. São Paulo: Feiras Industriais; 2008. p. 3-5. 
6 Zaharia M, Sahajwalla V, Khanna R, Koshy P, O'Kane P. Carbon/slag interactions between coke/rubber blends and EAF slag at $1550^{\circ} \mathrm{C}$. ISIJ International. 2009;49(I0):I5I6-I52I.

7 Sahajwalla V, Zaharia M, Rahman M, Khanna R, Saha-Chaudhury N, O'Kane P, et al. Recycling rubber tyres and waste plastics in EAF. Steel Research International. 201 I;82(5).

8 Massambani F. Comunicação interna. Araçariguama: Gerdau Aços Longos; 2016.

Recebido em: 19 Out. 2018

Aceito em: 3 Maio. 2019 